\title{
The curious case of COVID-19: Its murky origin, negligence and a botched international attempt for a cover-up
}

\author{
Ruby Dhar ${ }^{1}$, Karthikeyan Pethusamy², Joyeeta Talukdar ${ }^{3}$, Abhibrato Karmakar ${ }^{4}$, \\ Arun Kumar ${ }^{5}$, Subhradip Karmakar ${ }^{6}$
}

${ }^{1}$ Scientist, Room No-3020 Department of Biochemistry, All India Institute of Medical Sciences, New Delhi, India, ${ }^{2}$ Sr. Research Scholar, Room No-3018, Department of Biochemistry, All India Institute of Medical Sciences, New Delhi, India, ${ }^{3}$ Research Associate-I, Lab No-3018 Department of Biochemistry, All India Institute of Medical Sciences, New Delhi, India, ${ }^{4}$ Junior Research Fellow, Lab No-3018 Department of Biochemistry, All India Institute of Medical Sciences, New Delhi, India, ${ }^{5}$ Professor and Head, Department of Biochemistry, Jagannath Gupta Institute of Medical Sciences and Hospital, Budge Budge, Kolkata, India, ${ }^{6}$ Associate-Professor, Room No-3020, Department of Biochemistry, All India Institute of Medical Sciences, New Delhi, India

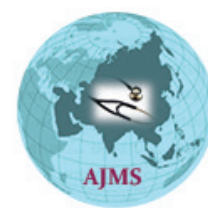

\section{A B S T R A C T}

COVD-19 caused due to SARS-CoV2, family of Coronaviridae, the order Nidovirales, and the genus Coronavirus. A zoonotic spillover infection from bats to humans through some intermediate host was proposed to be responsible for its origin. This theory gained traction and raised no concern because our experience with other pathogenic viruses with humans in the past followed a similar trajectory. However, what caught the attention are few missing pieces of the jigsaw puzzle that seems to defy logic. A detailed investigation revealed a trail of deception, negligence, and blotched attempt of cover-up.

Key words: COVID-19; Zoonosis; Wuhan Institute of Virology; SARS-CoV2; RaTG13; Gain of function; Pneumonia

\section{Access this article online}

Website:

http://nepjol.info/index.php/AJMS DOI: $10.3126 / a j m s . v 12 i 7.37669$

E-ISSN: 2091-0576

P-ISSN: 2467-9100

Copyright (c) 2021 Asian Journal of Medical Sciences

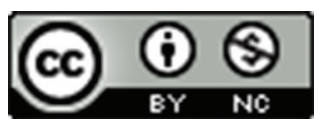

This work is licensed under a Creative Commons Attribution-NonCommercial 4.0 International License.

\section{INTRODUCTION}

Back in December 2019, little did the world knew that a crisis of an astronomical proportion is going to descend on humanity which will have not only such a profound influence on our life but will be nothing short of a documentary taken from the CIA files. It started as a natural accident, an unsuspecting spillover infection of a zoonotic virus into humans causing respiratory sickness and few deaths. After all, spillover infections are nothing new, with more than two-thirds of human viruses are zoonotic in origin, ${ }^{1}$ jumping from their animal reservoirs to humans. Rabies, anthrax, and histoplasmosis are a few in the past, where pathogenic agents have jumped host bodies ${ }^{2}$ but were limited to no secondary human-to-human transmission. However, others like the Ebola and Marburg filoviruses, the MERS and SARS coronaviruses, swine, and some avian flu viruses did show secondary inter-human transmission but were limited in small geographical boundaries. ${ }^{3,4}$ Epidemiologists estimate the degree of contagiousness of a pathogen by $R_{0}(R$ naught), a metric depicting the reproduction number. ${ }^{5} \mathrm{R}_{0}$ tells us the average number of 
people contracting a contagious disease from one infected person. It specifically applies to a population of people who were previously free of infection and haven't been vaccinated. $\mathrm{R}_{0}$ can take any three possible values; if less than 1 , each existing infection causes less than one new infection means that the disease will eventually die out by itself. If $R_{0}$ equals 1 , each current infection causes one new infection, which means that the disease will be active and stable in the population, but there are very few chances for an outbreak or an epidemic. The real threat comes when $\mathrm{R}_{0}$ is more than 1 , which means each existing infection causes more than one new infection. We are now clearly talking about disease amplification and will invariably be transmitted between people, potentially snowballing into an outbreak or epidemic. According to a study reported in Emerging Infectious Diseases, the $\mathrm{R}_{0}$ for COVID-19 has a median of 5.7. We can now perceive that we are dealing with a monster here, a sleeping Godzilla that could wake up any moment to create mayhem. It's worth mentioning for the readers that calculating $\mathrm{R}_{0}$ is not as simple as it sounds. It depends on numerous parameters, and very often, it is just an estimate rather than a universal constant. The aftermaths of COVID-19 were quite transparent, with the same images emerging everywhere in the world, albeit at different times. Human suffering in mass proportion along with high mortality, choking and paralyzing the healthcare system of even the most advanced nations of the world. The economy plummeted across the globe, and those lucky lots which seem spared of this pandemic were forced to live a life no better than the deceased. ${ }^{6}$ But what was not transparent is the origin of COVID-19. The world seems to deny accepting this gullible story that an isolated, accidental event at the Wuhan Animal market will spill over to 200 nations in the world, more that it will even go completely under the radar. What's even murkier is that Wuhan Institue of Virology (WIV) was, in fact, working on beta Coronavirus, and coincidentally, reports of a SARS-CoV2 like pneumonia were documented as early as in 2012 by miners in a remote location of Mojiang, some $1800 \mathrm{~km}$ far away from Wuhan. ${ }^{7}$ In fact, three miners succumb to the infection later on. Even the animal market at Wuhan is located far from where the horseshoe bats are actually found, making it hard to understand how the virus might have landed in Wuhan, making it ground zero; well, unless someone carried it intentionally. An intermediary host story of SARS-CoV2 jumping through pangolin seems futile to patch up the story. The world is still hunting for a credible natural ancestor for SARS-CoV2. Thanks to the joint efforts of few amateurs, online sleuths forming part of the DRASTIC (Decentralized Radical Autonomous Search Team Investigating COVID-19) group along with the pune couple, Dr. Mona Rahalkar and her husband Dr Ruhul Bahulikar (https://twitter.com/ MonaRahalkar). With their relentless effort, this seamlessly forgotten matter finally seen the light of the day. ${ }^{78}$ The matter of fact is that WIV was actively researching these viruses for a decade using inadequate safety protocols, which might have lead to an intentional or un-intentional lab leak triggering the pandemic. Following the trail, the group discovered that Dr. Shi Zhengli (aka batwomen of China) reported as early as in 2013 about a mysterious virus RaTG13, only to keep the scientific community blindfolded about its origin. ${ }^{9}$ What is spectacular is that the current SARS-CoV2 is 98\% similar to RaTG13, making it its direct known precursor. What Dr. Shi unknowingly left a trail is a short, obscure gene bank submission related to RaTG13. The genetic sequence for RaTG13 perfectly matched this short gene bank submission that Dr. Shi did report earlier was derived from a Yunnan bat virus. Or in other words, RaTG13 is the bat virus. Connecting the dots, it now became imminent that RaTG13 actually came from mining caves in the Mojiang region in Yunnan Province and not from Wuhan. What seems sinister is the strong possibility that the RaTG13 genetic backbone was fiddled and modified for quite some time as a part of "gain of function" mutations to derive the present-day SARS-CoV2. Further, several of the miners infected with RaTG13 in 2012 expired of pneumonia, with clinical symptoms very similar to the current COVID-19 symptoms. These facts was never disclosed to the rest of the world. What makes it even weird is that the Chinese gene bank records were all scooped overnight once the scientific community started raising suspicion. What are they afraid of if their hands are clean? The story doesn't end here. Back in 2012, the USA, with its NIH and the National Institue for Health and Infectious Disease (NIHAID), seems to have generously funded (6000000 USD) "gain of function" studies through an intermediary "EcoHealth Alliance" to WIV from 2014 and further renewed it in 2019 for another five years. ${ }^{10}$ This means someone in the USA was aware of these secret experiments by WIV, but kept it going by funding it. In 2020, an embargo on this funding was made only when cases of COVID19 started popping up. ${ }^{11-13}$ While these are going on, back in February 2020, a group of 20 scientists reported to Lancet, bluffing the lab leak theory and claiming that SARSCoV2 emerged by a Darwinian evolutionary process from its natural sources, squashing the lab leak theory. ${ }^{14}$ Interestingly, it was found that the Lancet letter was drafted and led by Peter Daszak, president of the EcoHealth Alliance, the same peoples who were funding the gain of function research. So he has a strong conflict of interest in this entire study.

\section{CONCLUDING REMARKS}

What seems plausible is that this virus appears to have originated naturally and transferred to humans as a process of zoonotic spillover, something that has been seen for SARS, MERS, etc. What is remarkable is a strong possibility that some gain of function mutations were tried and tested 
in the lab to enhance its infectivity or its human-to-human transmissibility, which WIV must have been aware of. These enhancements might have upgraded its R0 beyond 1, making it a recipe for a pandemic. A few doctoral thesis works were undertaken in WIV to explore more about these viruses. No one knows the real intention of these studies. A few published scientific articles by Dr. Zhengil clearly indicate WIV's obsession with these pathogenic viruses. Around 2015, Dr. Zhengli collected 1322 samples from bat caves, finding 293 diverse coronaviruses. Eight of these were beta-coronaviruses, and one of these eight was RaTG13, which had been described in a 2016 study under the name $\mathrm{RaBtCoV} / 4991 .{ }^{15}$ So they were really trying and testing these dangerous viruses, manipulating them and engineering it. It seems conceivable that an accidental lab leak might have taken place sometime in 2018-2019, and little was done either to prevent its further spread or, at the most, report it to WHO or other regulatory bodies. However, what was surely done was a purposeful act to hide all these facts and aggressively blocking an international effort for a more transparent investigation.

With over 40 lakh deaths and 18 crore cases worldwide, the COVID pandemic is unprecedented in magnitude and severity. As a result, developing economies were shattered, and millions had lost their job and livelihood. The world order has changed radically, and a new normal has set it. It is unlikely that the world might ever get back to its preCOVID stage. Under this ferocity, everyone has the right to know what started all this? We might never know what really happened, but we do have the fundamental right to ask why humankind has faced an unwanted crisis: was it our fate or sheer negligence that could have been avoided in the first place. Asking legitimate questions may provide some comfort even if there are no trustworthy answers.

\section{REFERENCES}

1. Zoonotic disease: emerging public health threats in the Region http://www.emro.who.int/fr/about-who/rc61/zoonotic-diseases.html

2. Rahman MT, Sobur MA, Islam MS, levy S, Hossain MJ, EI Zowalaty ME, et al. Zoonotic Diseases: Etiology, Impact, and Control. Microorganisms. 2020;8(9):1405.

https://doi.org/10.3390/microorganisms8091405
3. Letko M, Seifert SN, Olival KJ, Plowright RK and Munster VJ. Bat-borne virus diversity, spillover and emergence. Nat Rev Microbiol. 2020; 18: 461-471. https://doi.org/10.1038/s41579-020-0394-z

4. Banerjee A, Kulcsar K, Misra V, Frieman M and Mossman K. Bats and Coronaviruses. Viruses. 2019;11(1):41. https://doi.org/10.3390/v11010041

5. What is R. https://www.healthline.com/health/r-noughtreproduction-number

6. Coronavirus 'a devastating blow for world economy. https://www. bbc.com/news/business-52939846

7. Rahalkar MC and Bahulikar RA. Lethal Pneumonia Cases in Mojiang Miners (2012) and the Mineshaft Could Provide Important Clues to the Origin of SARS-CoV-2. Front Public Health. 2020;8:581569.

https://doi.org/10.3389/fpubh.2020.581569

8. The Lab-Leak Hypothesis for COVID-19 Is Becoming a Conspiracy Theory.

https://science.thewire.in/the-sciences/the-lab-leak-hypothesisfor-covid-19-is-becoming-a-conspiracy-theory

9. Zhou P, Yang XL, Wang XG, Hu B, Zhang L, Zhang W, et al. A pneumonia outbreak associated with a new coronavirus of probable bat origin. Nature. 2020; 579: 270-273.

https://doi.org/10.1038/s41586-020-2012-7

10. Heinous!': Coronavirus researcher shut down for Wuhan-lab link slams new funding restrictions.

https://www.nature.com/articles/d41586-020-02473-4

11. NIH Presses U.S. Nonprofit for Information on Wuhan Virology Lab. https://www.wsj.com/articles/nih-presses-u-s-nonprofit-forinformation-on-wuhan-virology-lab-11597829400

12. Why The U.S. Government Stopped Funding A Research Project On Bats And Coronaviruses.

h t t p s : / / w w w. n p r.org/s e c t i o n s / goatsandsoda/2020/04/29/847948272/why-the-u-sgovernment-stopped-funding-a-research-project-on-bats-andcoronaviru? $\mathrm{t}=1623184181431$

13. NIH Cancels Funding for Bat Coronavirus Research Project. https://www.the-scientist.com/news-opinion/nih-cancelsfunding-for-bat-coronavirus-research-project-67486

14. Calisher C, Carroll D, Colwell R, Corley RB, Daszak P, Drosten C, et al. Statement in support of the scientists, public health professionals, and medical professionals of China combatting COVID-19. Lancet. 2020;395(10226):e42-e43.

https://doi.org/10.1016/S0140-6736(20)30418-9

15. The Frightening COVID Origin Charge Against China's Shi Zhengli, Wuhan's Bat Virologist.

https://www.republicworld.com/technology-news/science/thefrightening-covid-origin-charge-against-chinas-shi-zhengliwuhans-bat-virologist.html

\footnotetext{
Authors Contribution:

RD, SK- Conceptualized and drafted the article; KP- Helped with references, writing, and collecting facts and data; JT,Abhi K assisted in references and formatting; AK-Helped with critical evaluation and discussion in improving the manuscript; SK- Overseen the entire work and helped in framing the concepts

Work attributed to:

Department of Biochemistry, All India Institute of Medical Sciences,New Delhi, India, 110029.

Orcid ID:

Dr. Ruby Dhar - (1) https://orcid.org/0000-0003-3600-6554

Joyeeta Talukdar - (i) https://orcid.org/0000-0002-4922-2283

Abhibroto Karmakar - id https://orcid.org/0000-0002-9697-9107

Dr. Arun Kumar - ib http://orcid.org/0000-0002-8800-0296

Dr. Subhradip Karmakar - (10) https://orcid.org/0000-0002-4757-8729

Source of Support: None, Conflict of Interest: None.
} 